\title{
Condensation Reaction and Crystallization of Urea- Formaldehyde Resin during the Curing Process
}

\author{
Zhongjian Ding, ${ }^{\mathrm{a}, *}$ Zhongqiang Ding, ${ }^{\mathrm{b}, *}$ Tianlin Ma, ${ }^{\mathrm{a}}$ and Hua Zhang ${ }^{\mathrm{a}}$ \\ Urea-formaldehyde (UF) resins were synthesized with different molar \\ ratios and solid contents, and simultaneously they were cured under \\ conditions of different $\mathrm{pH}$ values. The curing behaviors of cured UF resins \\ were examined by synchronous thermal analysis (TG-DSC). The \\ crystallinity of cured UF resin was analyzed by X-ray diffractometry. The \\ gel time of cured UF resin was recorded by chemical methods. The results \\ indicate that condensation reactivity leads condensation reaction and \\ crystallization to play various roles during the curing process of UF resin. \\ The condensation reaction and crystallization in the curing process \\ interact to result in different structures of cured resin. A new mechanism \\ for UF resin curing (reaction-crystallization) is thus proposed.
}

Keywords: Urea-formaldehyde resin; Curing; Condensation reactivity; Condensation reaction; Crystallization; Crystallinity

Contact information: a: College of Materials Science and Chemical Engineering, Chuzhou University, 239000, Anhui province, China; $b$ : Singapore Institute of Technology, Singapore;

*Corresponding authors: zjding@chzu.edu.cn; ding.zhongqiang@singaporetech.edu.sg

\section{INTRODUCTION}

Urea-formaldehyde resin (UF resin) is one of the most important adhesives for the assembly of man-made wood-based panels, such as MDF, plywood, and particleboard. Commonly, thermosetting urea-formaldehyde (UF) resin is cured by condensation reaction under acidic conditions.

The curing process of UF resin has been studied by using differential scanning calorimetry (DSC) technology. Szesztay et al. $(1993,1996)$ found that an exothermic peak (condensation reaction) and an endothermic peak (decomposition of methylene-ether linkages) appeared in the DSC curve. In a high pressure DSC cell, the endothermic effect shifted to higher temperature and avoided disturbing the exothermic peak. Xing et al (2005) studied the effect of catalyst content on curing behavior of UF resin under high pressure conditions. The parameters of the exothermic peak showed that the condensation reactivity of resin increased with increment of $\mathrm{pH}$ value in the resin system. Pizzi's team (2019) analyzed the effect of initial $\mathrm{F} / \mathrm{U}$ molar ratio on reaction heat, onset temperature, exothermic and endothermic peak temperatures of the DSC curve. The results showed that the initial molar ration obviously affected physico-mechanical properties of the boards.

The studies also found that cured UF resin has a crystalline state that does not exist in other thermosetting resins such as phenolic resins, epoxy resins, etc. (Gupta et al. 1985). The crystalline structure of the cured UF resin is inherent in UF resin, especially in the UF resin with low molar ratios of formaldehyde to urea (F/U molar ratio) (Nuryawan et al.2016). The crystallinity of cured resin is affected by molar ratios, temperature of curing process, and curing agents. The crystallinity of the cured UF resin increases as the F/U molar ratio decreases (Park and Causin 2013; Singh et al. 2014; Nuryawan et al. 2017). 
The crystallinity of cured resin was inversely proportional to the degree of branched structure of cured resin (Nuryawan et al. 2015; Park and Jeong 2011; Ding and Tian 2017).

Based on the previous studies, there is not only a condensation reaction but also crystallization during the UF resin curing process. The impact of the factors, such as F/U molar ratio and curing agent, etc., on condensation reactivity or crystallinity has been reported. However, the study of the combined effects of condensation reaction and crystallization on curing mechanism of UF resin is very limited.

Therefore, in the present work, the UF resins with different condensation reactivity were obtained by adjusting final $\mathrm{F} / \mathrm{U}$ molar ratio, solid content, and $\mathrm{pH}$ value of curing condition. The gel time, which characterizes the reactivity, as well as the crystallinity of cured resin, which characterizes the structure of resin, were measured under same $\mathrm{pH}$ conditions. The TG-DSC curves were obtained under normal pressure. The curing processes of UF resins with different condensation reactivity were studied. The results clarify the variety of curing mechanism of UF resin with different condensation reactivity. Accurate understanding of the curing mechanism of UF resin is beneficial to the development of UF resin with low-formaldehyde release and high-performance.

\section{EXPERIMENTAL}

\section{Materials}

Reagent-grade formaldehyde (37\%), sodium hydroxide, formic acid, and hydrochloric acid were purchased from Shanghai Chemical Reagent Ltd., China. Industrial-grade Urea was provided by ChuzhouJinhe Chemical Industry Ltd., China.

\section{Preparation of UF Resins}

All resins were synthesized in the laboratory. The synthesis of all UF resins was a typical three-step procedure (alkaline-acidic-alkaline). First, formaldehyde ( $\mathrm{F}=250 \mathrm{~g}$ ) was poured into a three-necked flask and adjusted to $\mathrm{pH} 7.5$ to $\mathrm{pH} 8.0$ with $20 \%$ sodium hydroxide solution. The first amount of urea $\left(\mathrm{U}_{1}=94.4 \mathrm{~g}\right)$ was added to give the $\mathrm{F} / \mathrm{U}$ molar ratio of 2.0. The mixture was heated to $90{ }^{\circ} \mathrm{C}$ and maintained at this temperature for 30 minutes. The condensation reaction took place by adding formic acid (10\%) to obtain a $\mathrm{pH}$ of 4.6 to 4.8 until endpoint 1 was reached. The $\mathrm{pH}$ was adjusted to 5.0 with sodium hydroxide solution, and the second amount of urea $\left(\mathrm{U}_{2}=23.5 \mathrm{~g}\right)$ was added to give the $\mathrm{F} / \mathrm{U}$ molar ratio of 1.60 . The temperature was maintained at 85 to $90{ }^{\circ} \mathrm{C}$ until the endpoint 2 was reached. The endpoint was determined by the cloudy appearance when the solution mixture was dropped into a beaker of water at certain temperature (endpoint 1: $20{ }^{\circ} \mathrm{C}$, endpoint 2: $40^{\circ} \mathrm{C}$ ). When endpoint 2 was reached, the $\mathrm{pH}$ was adjusted to 7.5 to 8.0 with the sodium hydroxide solution. The third amount of urea $\left(\mathrm{U}_{3}\right)$ was added. The reaction mixture was maintained at $70{ }^{\circ} \mathrm{C}$ for $30 \mathrm{~min}$. Finally, the mixture was cooled to ambient temperature. The $\mathrm{pH}$ was adjusted to 7.5 to 8.0 again. Various amounts of $\mathrm{U}_{3}\left(\mathrm{U}_{3}=0 \mathrm{~g}\right.$, $16.9 \mathrm{~g}, 39.4 \mathrm{~g}, 61.9 \mathrm{~g}$, or $80.8 \mathrm{~g}$ ) had different final F/U molar ratios (the F/U molar ratio $=1.60,1.40,1.20,1.05$, and 0.95 , respectively). The UF resin with the F/U molar ratio of 1.60 was dehydrated on vacuum conditions to obtain the resins with different solid contents $(50 \%, 58 \%$, and $67 \%)$. The solid content of UF resin was measured according to GB/T14732 (2006). 


\section{Preparation of Samples for Measure}

Liquid resin with different $\mathrm{pH}$ values

The $\mathrm{pH}$ values of all resins were adjusted to 7.5, 4.5, 4.0, and 3.0 with sulfuric acid solution $(20 \%)$.

In other studies, the $\mathrm{pH}$ value of UF resin used to be adjusted by ammonium salt, such as $\mathrm{NH}_{4} \mathrm{Cl}$. The $\mathrm{pH}$ value was affected by the formaldehyde produced during the UF resin curing process. This meant that the $\mathrm{pH}$ value changed with the variety of the amount of formaldehyde during the curing process (Xing et al. 2005; Dazmiri et al. 2019). To maintain $\mathrm{pH}$ values during the UF resin curing process, the sulfuric acid solution was used to adjust the $\mathrm{pH}$ values directly.

\section{Powdered cured resin}

The resins with different $\mathrm{pH}$ values were cured in the oven at $120{ }^{\circ} \mathrm{C}$ for $2 \mathrm{~h}$. The cured resins were ground into particles and sieved to obtain particles between 80 mesh and 120-mesh for the XRD test.

\section{Gel Time Measurement}

The gel time of the liquid resins with different $\mathrm{pH}$ values was measured at $100{ }^{\circ} \mathrm{C}$ by a gel time meter (Sunshine 22A, Shanghai, China). An average of three replications was used for each measurement.

\section{TG-DSC Measurement}

TG-DSC measurements were carried out with a synchronous thermal analyzer (SDT Q600, TA, City, USA) with the heating rate of $5 \mathrm{~K} / \mathrm{min}$ in dynamic nitrogen atmosphere $(100 \mathrm{~mL} / \mathrm{min})$. The mass of the samples was 10 to $15 \mathrm{mg}$. The temperature of samples ranged from $30{ }^{\circ} \mathrm{C}$ to $200{ }^{\circ} \mathrm{C}$. The TG-DSC test was carried out with an open crucible. All samples were the same as those in the gel time test.

\section{X-Ray Diffraction (XRD)}

An X-ray diffractometer (D8 Advance, Bruker, Karlsruhe, Germany) was used to investigate the crystallinity of cured UF resins. The powdered cured resins were analyzed at ambient temperature using a CuKa-1 X-ray source with a wavelength $(\lambda)$ of $1.5406 \AA$. The angle of incidence changed from $10^{\circ}$ to $70^{\circ}$ by steps of $0.02^{\circ} / \mathrm{min}$.

The XRD diffractgram was analyzed by MDI jade5.0 software. The crystallinity of cured UF resin was obtained.

\section{RESULTS AND DISCUSSION}

\section{TG-DSC Curves of Urea-Formaldehyde Resin}

The UF resin was cured with the F/U molar ratio of 1.60 and solid content of $50 \%$ under conditions of $\mathrm{pH} 7.5$ and 3.0, respectively. Figure 1 shows the TG-DSC curves of the UF resins curing. There are two endothermic peaks (peak 1 and peak 2) on every DSC curve, and these peaks are accompanied by significant mass loss appearing on the TG curve.

Under the pH 7.5 condition, the water in initial resin is quickly evaporated with increment of temperature before peak 1. Due to the water loss, the liquid state of resin changes to the gel state between peak 1 and peak 2 (Nuryawan et al. 2017). The resistance 
of water diffusing from interior to surface of resin in gel state increases, and water evaporation rate decreases. When temperature reaches peak 2 , the formaldehyde from decomposition of methylene-ether linkages, as well as small amount of initial water, is evaporated from the resin, accompanying the endothermic effect (Szesztay et al. 1993).

The temperatures at peak 1 and endothermic heat at $\mathrm{pH} 3.0$ are lower than those at $\mathrm{pH}$ 7.5. This indicates that the condensation reaction has taken place. The condensation reaction is an exothermic reaction. The exothermic heat offsets some endothermic heat. No exothermic peak appears between peaks 1 and 2 on the DSC curve because the exothermic effect is covered by endothermic effect of water evaporation (Siimer et al. 2003; Zorba et al. 2008). The condensation reaction will increase the degree of cross-linking of resin. A higher degree of cross-linking in the structure leads to higher diffusion resistance. More water (reaction water) and methylene-ether linkages are produced by the condensation reaction. Thus, it is known that there will be greater amounts of water and methylene-ether linkages in the resin. Here, comparing to the TG curves of $\mathrm{pH} 3.0$ and 7.5 between peaks 1 and 2, the evaporation rate of water at $\mathrm{pH} 3.0$ is obviously lower than that at $\mathrm{pH} 7.5$. The mass loss for peak 2 at $\mathrm{pH} 3.0$ is more than that at $\mathrm{pH}$ 7.5. This means that more of the initial water, reaction water, and methylene-ether linkages are left in the resin in gel state before peak 2 . However, those substances are all quickly evaporated at peak 2 (Siimer et al. 2003; Dazmiri et al. 2019).

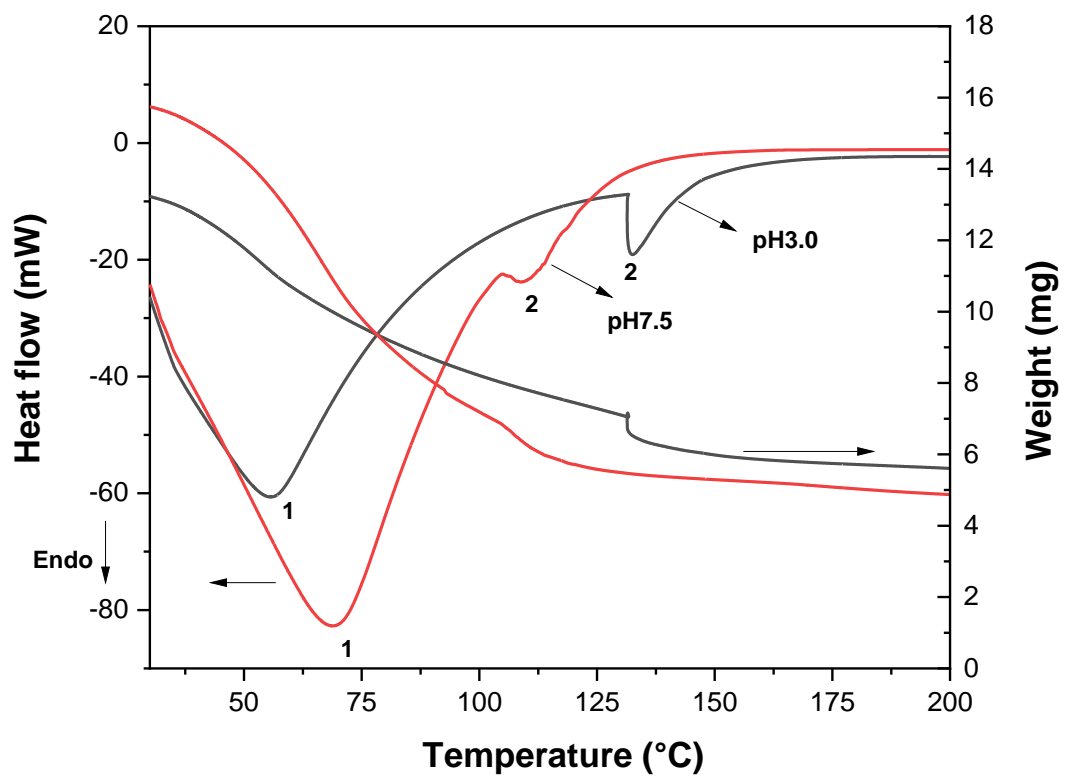

Fig. 1. TG-DSC curves of UF resin with F/U molar ratio of 1.60 and solids content of $50 \%$

Figure 2 shows the TG-DSC curves for when the UF resins with a mole ratio of 1.60 and various solid contents $(50 \%, 58 \%$, and 67\%) were cured under the condition of $\mathrm{pH}$ 3.0. Figure 3 shows the gel time and mass loss of the resins corresponding to the peak 2. The gel time decreased with the increment of solid contents. This means that the condensation reactivity of the resin increased with the increment of solid contents. Figure 2 also shows that the amount of the evaporated substance at peak 2 (mass loss) increased with the increment of condensation reactivity rather than with the increment of water content of the initial resin. This indicates that the evaporated substance at peak 2 was 
mainly derived from the reaction water as well as due to the formaldehyde from the decomposition of methylene-ether linkages.

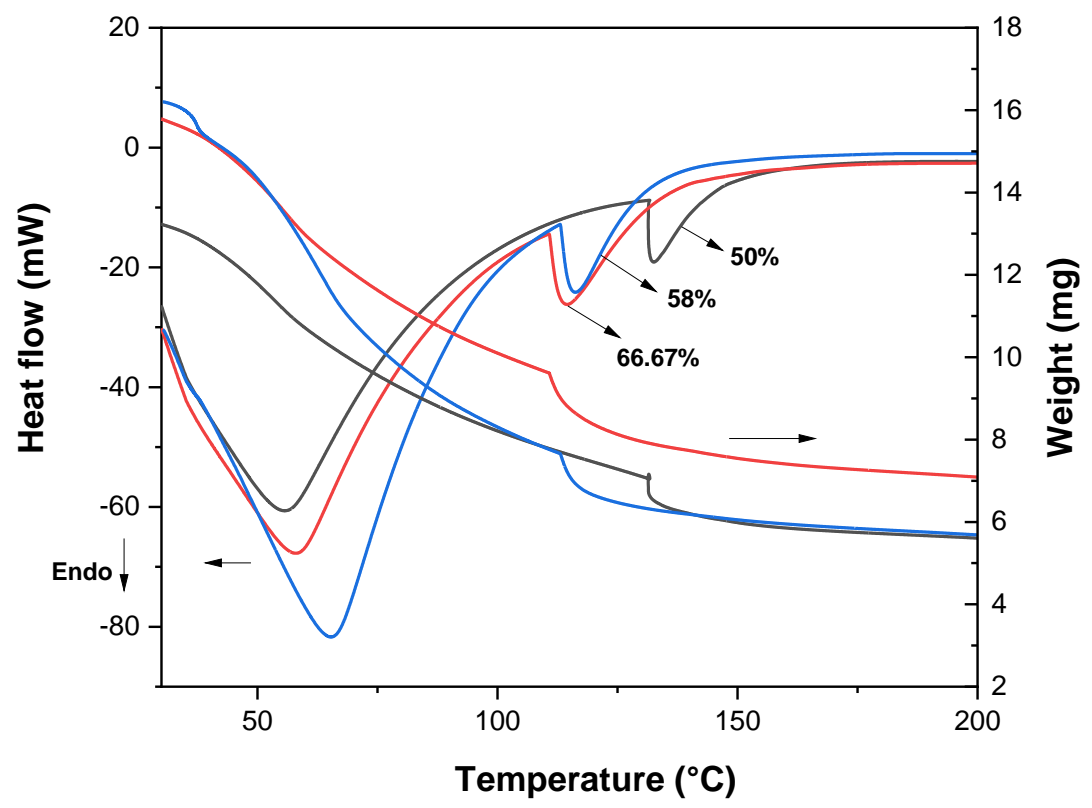

Fig. 2. TG-DSC curves of UF resin with F/U molar ratio of 1.60 and different solids content under $\mathrm{pH} 3.0$ condition

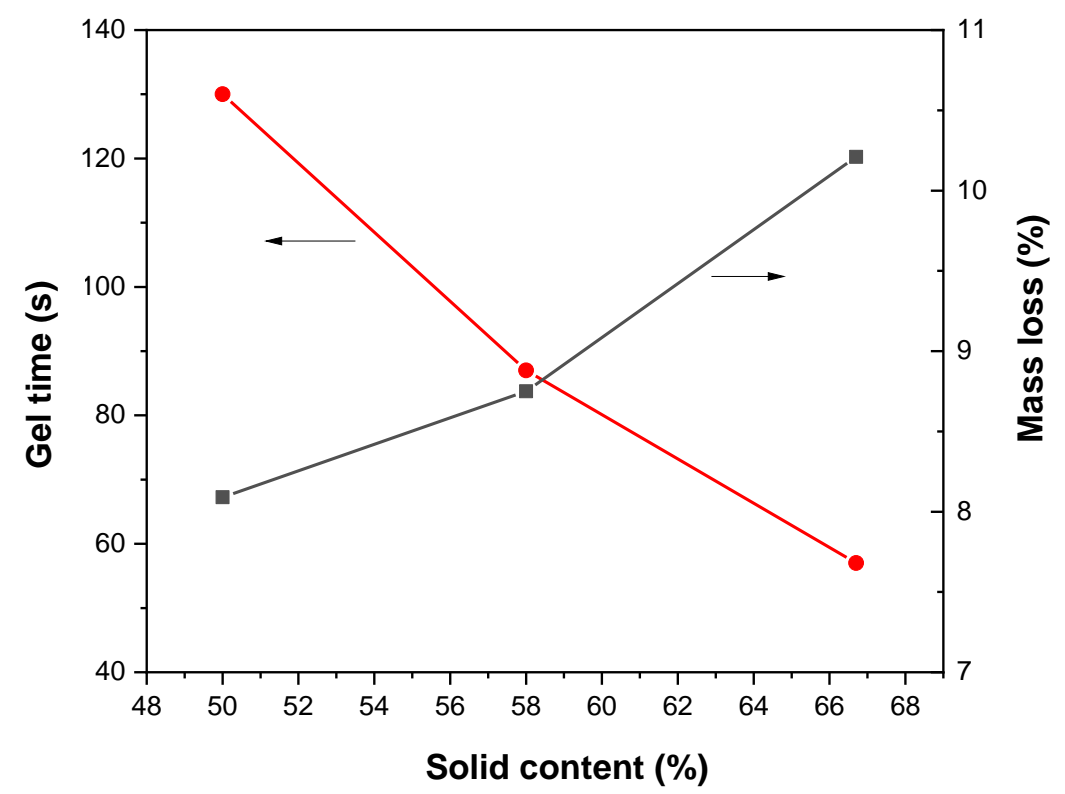

Fig. 3. Gel time and mass loss corresponding to peak 2 of UF resin with F/U molar ratio of 1.60 curing under condition of $\mathrm{pH} 3.0$

Figure 4 shows that the temperature at peak $2\left(T_{\mathrm{p}}\right)$ increased with the increment of the gel time of the resin under $\mathrm{pH} 3.0$. This means that $T_{\mathrm{p}}$ decreased with the increment of the condensation reactivity of resin. The studies found that, for the UF resin with higher 
F/U molar ratios, the increment of condensation reactivity could result in a higher degree of branching of cured resin. The branched network structure facilitated water penetration into the interior of cured resin, which led to more hydrolysis (Park and Jeong 2011; Ding and Tian 2017). In other words, the branched network structure facilitates water and formaldehyde to evaporate from interior of resin in gel state at lower temperature as well (Siimer et al. 2003). The value of $T_{\mathrm{p}}$ is inversely proportional to diffusion resistance of substance evaporation in resin. It is reasonable to conclude that $T_{\mathrm{p}}$ is affected by condensation reactivity, the gelling process, and the degree of branched structure of the cured resin.

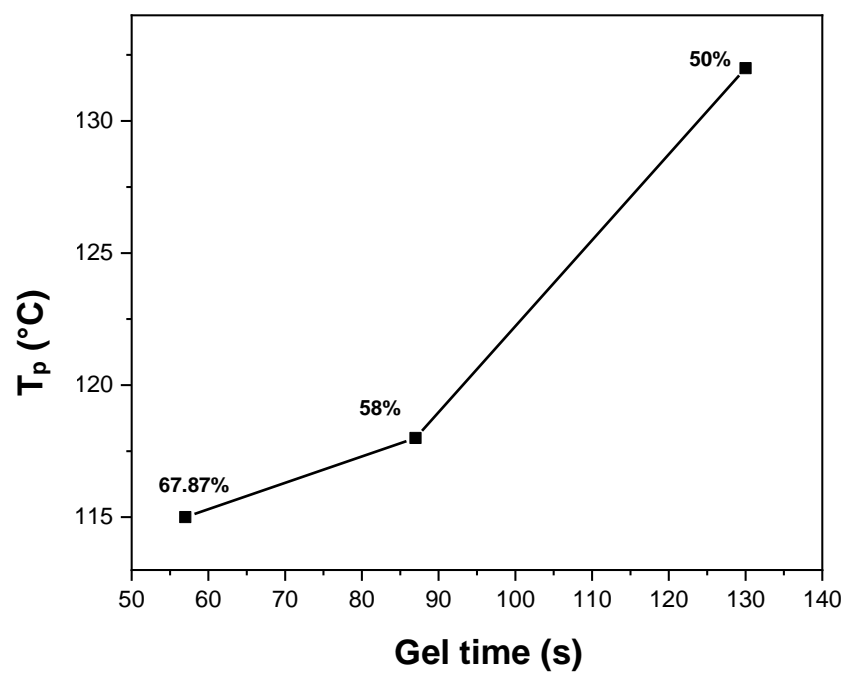

Fig. 4. Gel time and $T_{\mathrm{p}}$ of peak 2 of UF resin with $\mathrm{F} / \mathrm{U}$ molar ratio of 1.60 curing under condition of $\mathrm{pH} 3.0$

\section{Condensation Reaction and Crystallization of Urea-Formaldehyde Resin during Curing Process under Conditions of Different pH}

Figure 5 shows the peak 2 of the DSC curve, when the UF resin with the F/U molar ratio of 1.60 was cured under conditions of $\mathrm{pH} 3.0, \mathrm{pH} 4.0$, and $\mathrm{pH} 4.5$, respectively. The $T_{\mathrm{p}}$ value of peak 2 decreased with the decrement of $\mathrm{pH}$ values. This means that the water and formaldehyde in resin evaporated more easily with the increment of the condensation reactivity of UF resin. However, Fig. 6 shows that $T_{\mathrm{p}}$ increases with the decrement of the $\mathrm{pH}$ value, when the UF resin with the $\mathrm{F} / \mathrm{U}$ molar ratio of 0.95 was cured under conditions of $\mathrm{pH} 3.0, \mathrm{pH} 4.0$, and $\mathrm{pH} 4.5$, respectively. This means that it is difficult to evaporate water and formaldehyde in resin with the increment of the condensation reactivity of UF resin. In summary, there are different impacts of condensation reactivity of UF resins on the structure of cured resin with different $\mathrm{F} / \mathrm{U}$ molar ratios.

Figure 7 (a) shows that, for UF resin with the F/U molar ratio of 1.60, the structure of cured UF resin was amorphous. Figure 8 shows that the crystallinity of cured UF was near to zero and that it was not affected by the $\mathrm{pH}$ value. Only the value of $T_{\mathrm{p}}$ was affected by the $\mathrm{pH}$ value. This indicates that the condensation reaction enhanced the degree of branching of cured UF resin and limited the crystallization of the UF resin during the curing process. The condensation reaction played a major role during the curing process for the UF resin with the F/U molar ratio of 1.60 . 


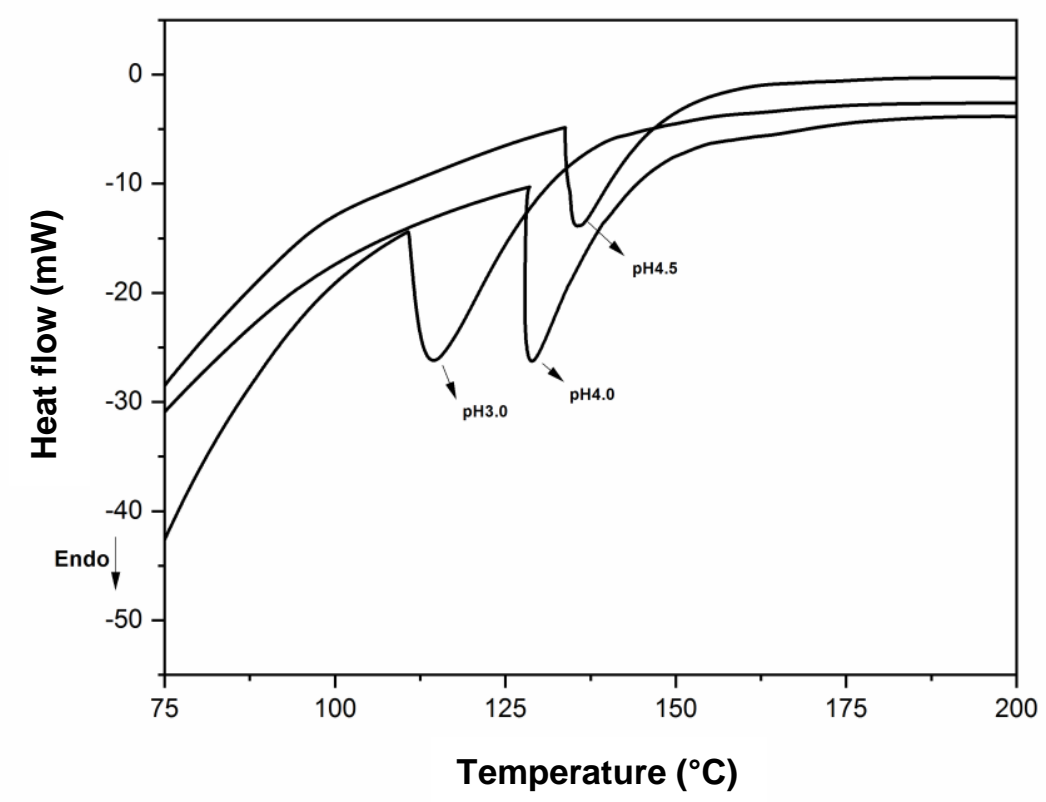

Fig. 5. Peak 2 on DSC curves of UF resin with F/U molar ratio of 1.60 curing with different $\mathrm{pH}$

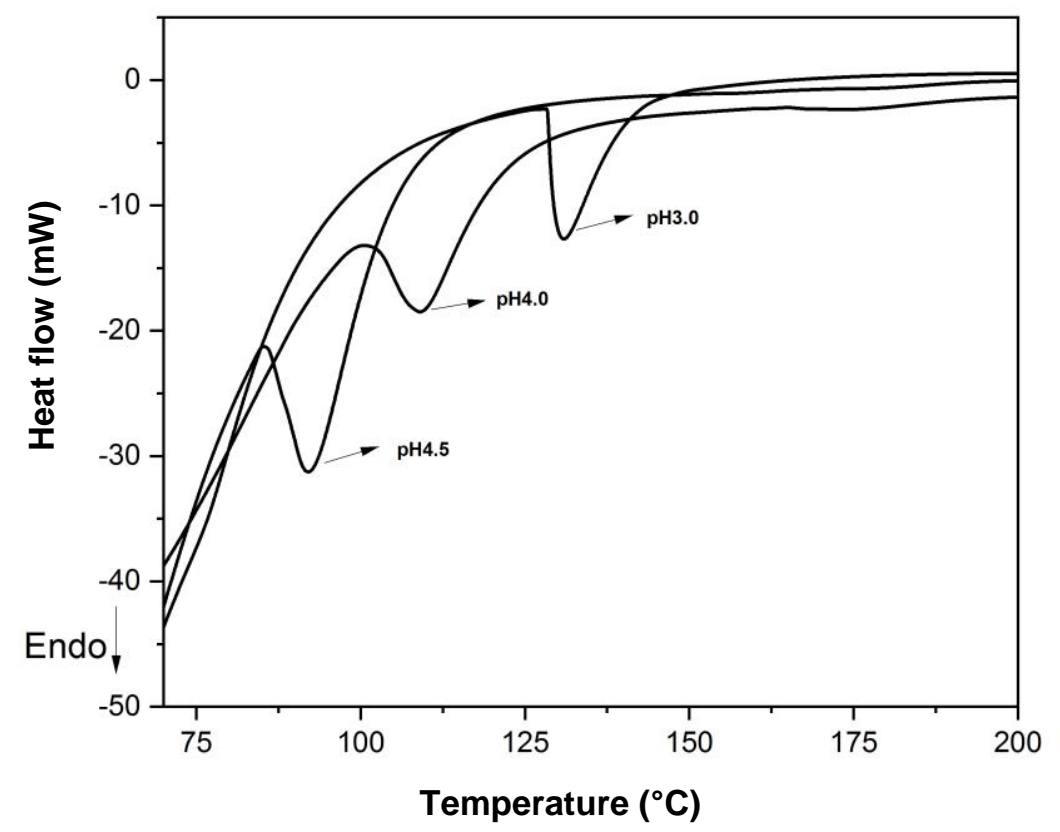

Fig. 6. Peak 2 on DSC curves of UF resin with $F / U$ molar ratio of 0.95 curing with different $\mathrm{pH}$

Figures 7(b) and 8 show that, for the UF resin with the F/U molar ratio of 0.95 , the crystallinity of cured resin increased with the decrement of the $\mathrm{pH}$ value. This means that the condensation reactivity of the UF resin enhanced the crystallinity and decreased the degree of branched structure of cured resin. As we have known, the condensation reactivity of UF resin with a low molar ratio was lower than that with a high molar ratio (Park et al. 2006). When UF resin with the F/U mole ratio of 0.95 was cured, the macromolecular 
chains firstly intertwined with each other and arranged themselves in an orderly way because of lower reactivity. The crystal structure was formed in the cured resin (Nuryawan et al. 2017). The condensation reaction occurred between adjacent reactive groups in the crystal region. New covalent bonds fastened the molecular chains in the crystal zone and so the crystallinity increased. The agglomeration and crystallization occurred before the condensation reaction. In other words, crystallization played a major role during the curing for UF resin with the $\mathrm{F} / \mathrm{U}$ mole ratio of 0.95 , but the condensation reaction only enhanced the crystallization.

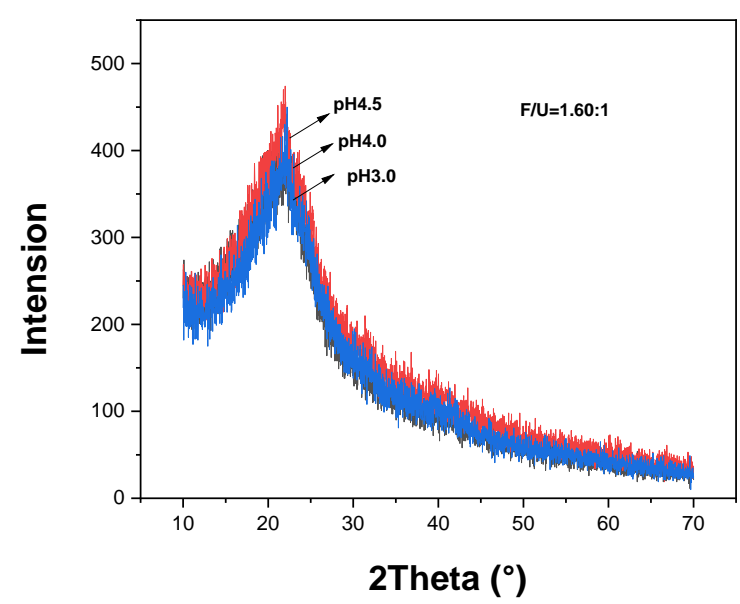

a

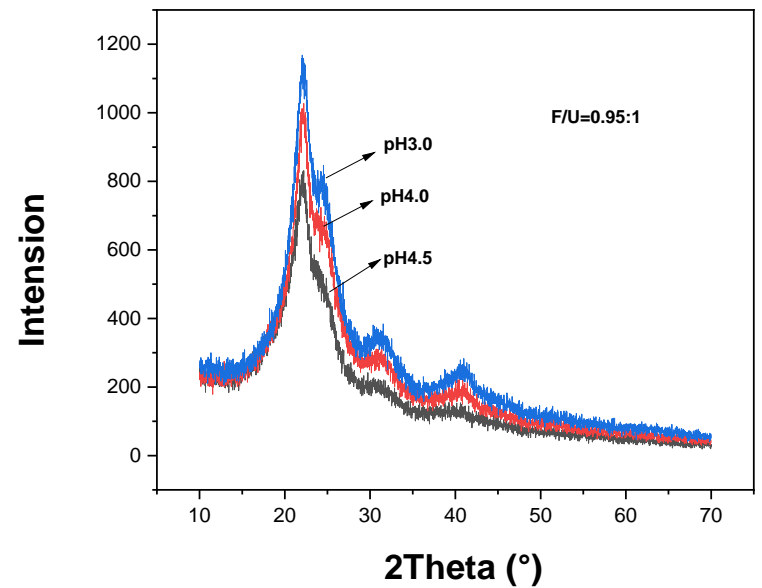

b

Fig. 7. X-ray diffractograms of cured UF resins with F/U molar ratio of 1.60 and 0.95 under different $\mathrm{pH}$ conditions

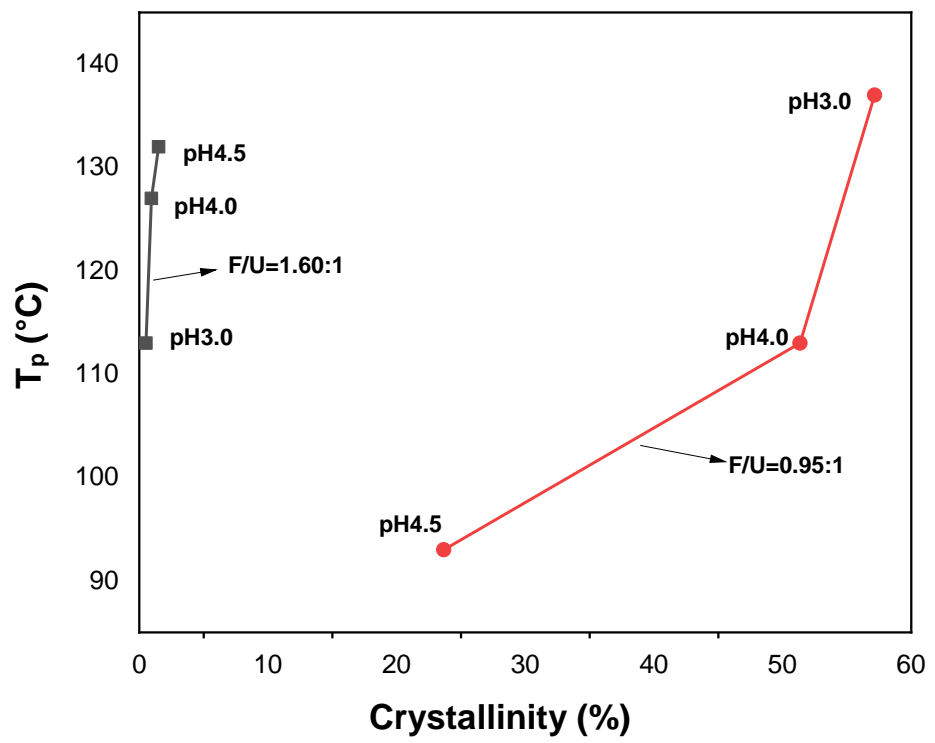

Fig. 8. $T_{\mathrm{p}}$ of Peak 2 and crystallinity of cured resin with $\mathrm{F} / \mathrm{U}$ molar ratio of 1.60 and 0.95 under different $\mathrm{pH}$ conditions 


\section{Condensation Reaction and Crystallization of Urea-Formaldehyde Resin with Different Molar Ratio during the Curing Process}

Figure 9 shows the peak 2 of DSC curves, when UF resins with different molar ratios $(1.60,1.40,1.20$, and 0.95 , respectively) were cured under the condition of $\mathrm{pH} 3.0$. The value of $T_{\mathrm{p}}$ increased when the $\mathrm{F} / \mathrm{U}$ mole ratio decreased. This means that the evaporation resistance of water and formaldehyde in resin increased with the decrement of $\mathrm{F} / \mathrm{U}$ molar ratios. Figure 10 shows that the crystallinity of the cured UF resins obviously increased with the decrement of F/U molar ratios. In other words, the degree of branching of the cured UF resin decreased with the decrement of F/U molar ratios. Figure 11 shows that the gel time of the UF resins increased and the mass loss decreased when the F/U molar ratio decreased from 1.60 to 0.95 . This indicates that the reactivity and degree of condensation reaction decreased with the downturn of F/U mole ratios during the curing process. In other words, the influence of condensation reaction decreased in the cured resin and that of crystallization increased with the decrement of $F / U$ molar ratios.

Figure 12 shows the $T_{\mathrm{p}}$ at peak 2, when UF resins with different F/U mole ratios were cured under conditions of different $\mathrm{pH}$ values. When the $\mathrm{F} / \mathrm{U}$ mole ratio gradually declined from 1.60 to 0.95 , the variations of $T_{\mathrm{p}}$ with the decrement of $\mathrm{pH}$ values switched from decrement to increment. When the $\mathrm{F} / \mathrm{U}$ mole ratio was 1.05 , the variation of $T_{\mathrm{p}}$ with $\mathrm{pH}$ values was very limited. This result indicates that the turning point of importance of condensation or crystallization during resin curing was around the F/U mole ratio of 1.05 . When the $\mathrm{F} / \mathrm{U}$ molar ratio was higher than 1.05 , the condensation reaction played a major role. However, when the F/U molar ratio was lower than 1.05 , the crystallization played a major role.

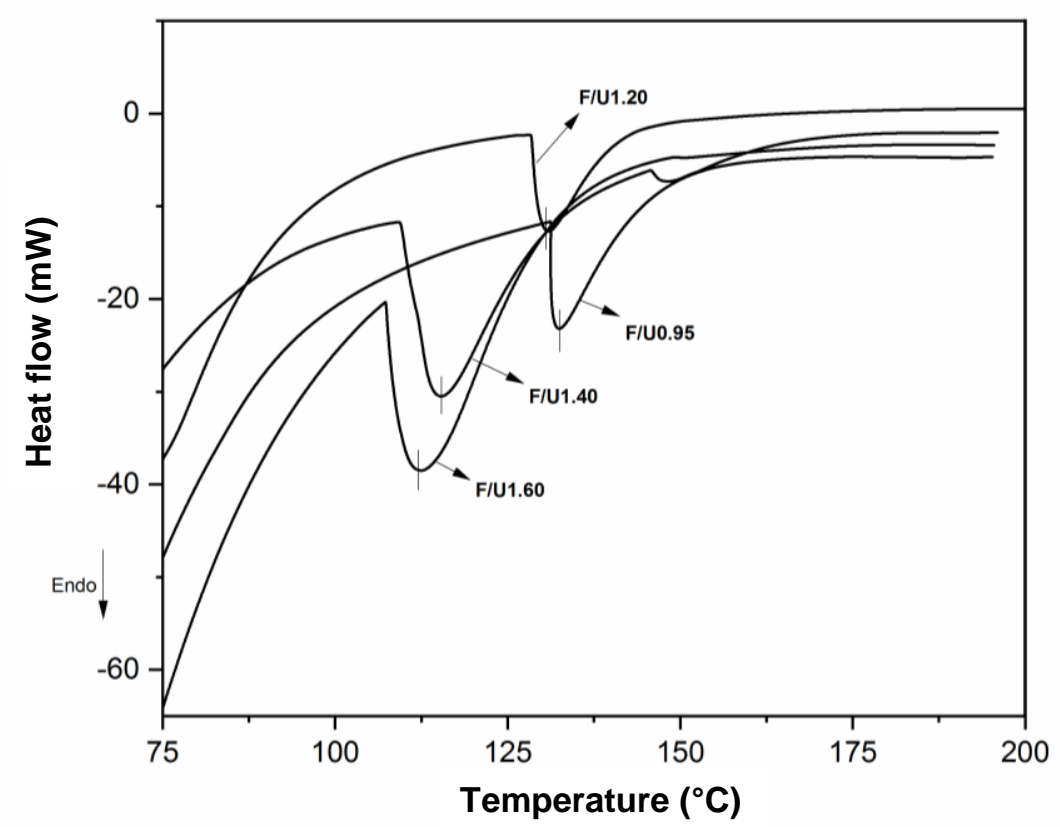

Fig. 9. Peak 2 on DSC curves of UF resin with different $F / U$ molar ratios of curing with $\mathrm{pH} 3.0$ 


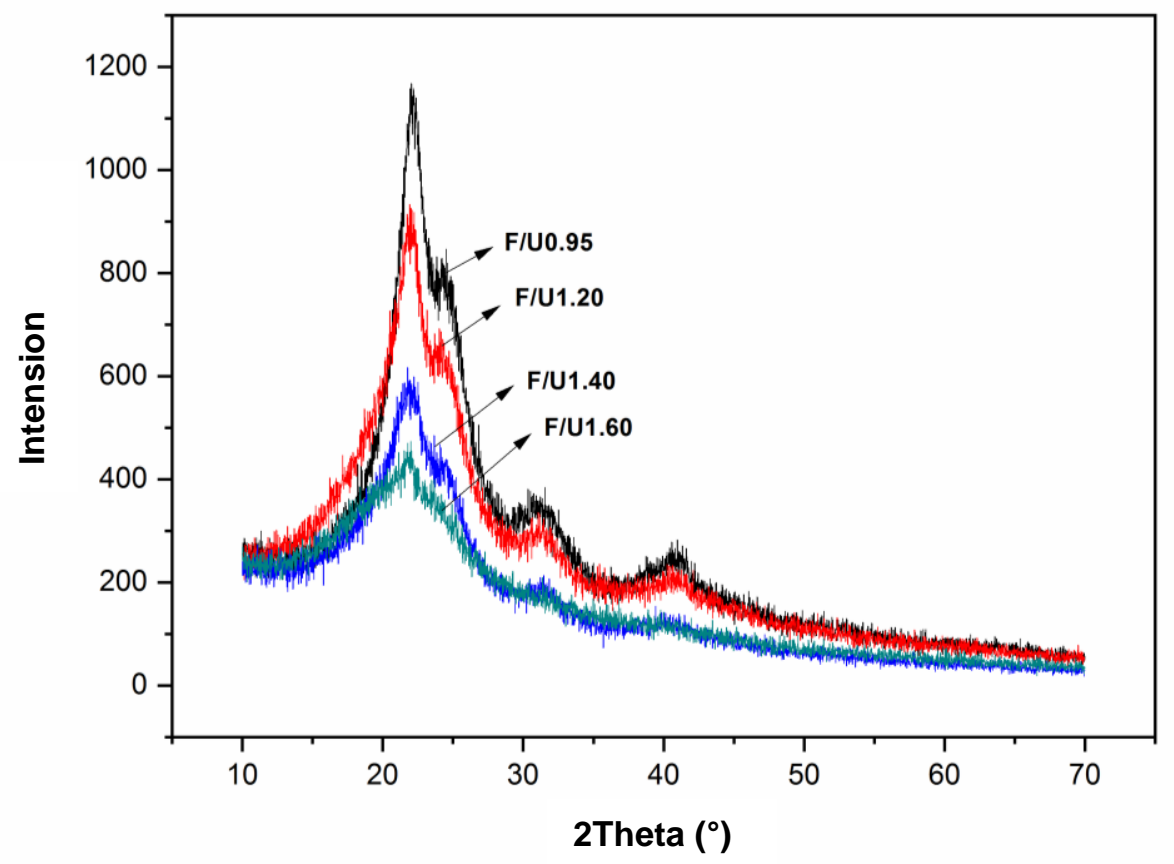

Fig. 10. X-ray diffractograms of cured UF resins with different $F / U$ molar ratios at $\mathrm{pH} 3.0$

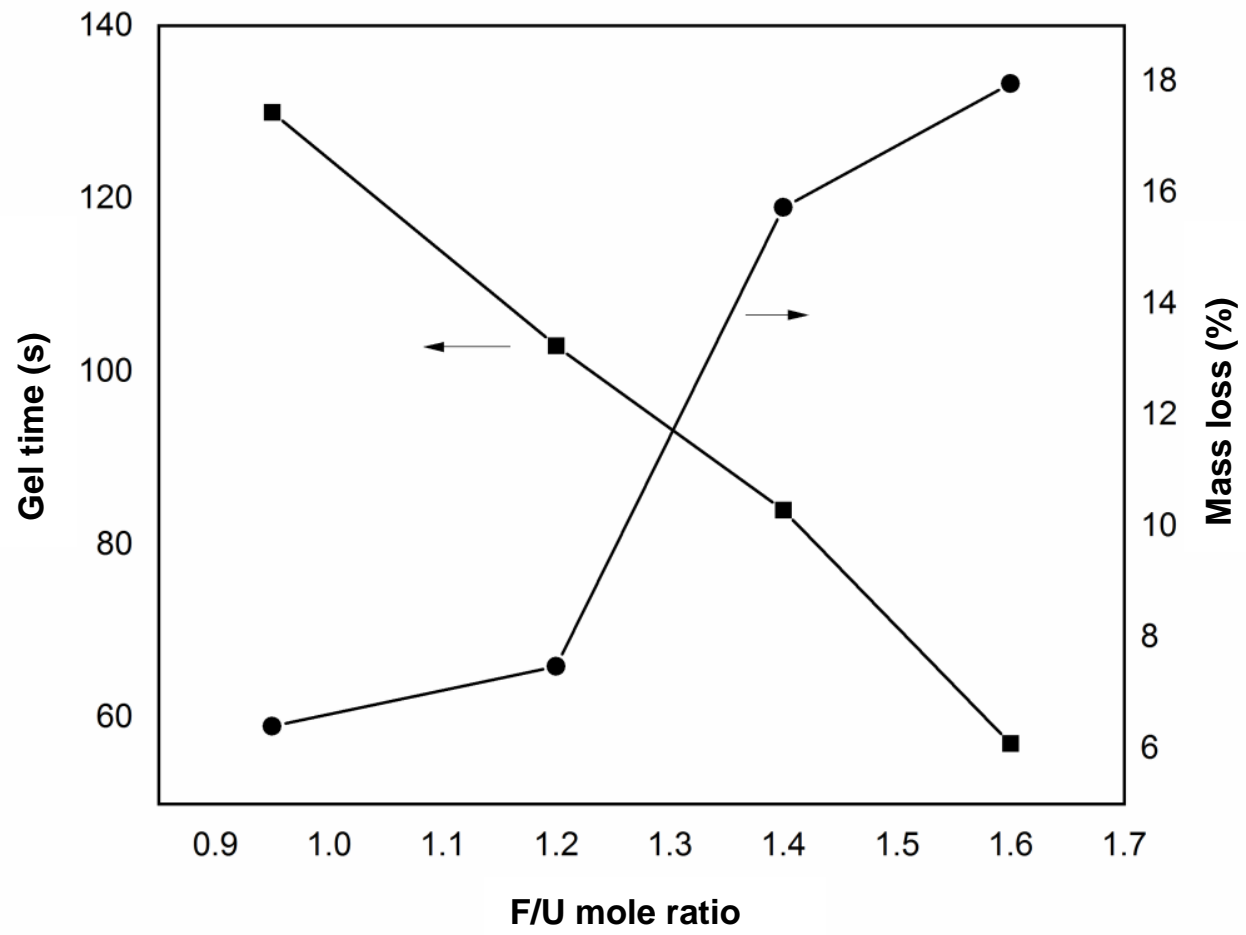

Fig. 11. Gel time and mass loss corresponding to peak 2 of UF resin with different F/U molar ratios curing under condition of $\mathrm{pH} 3.0$ 


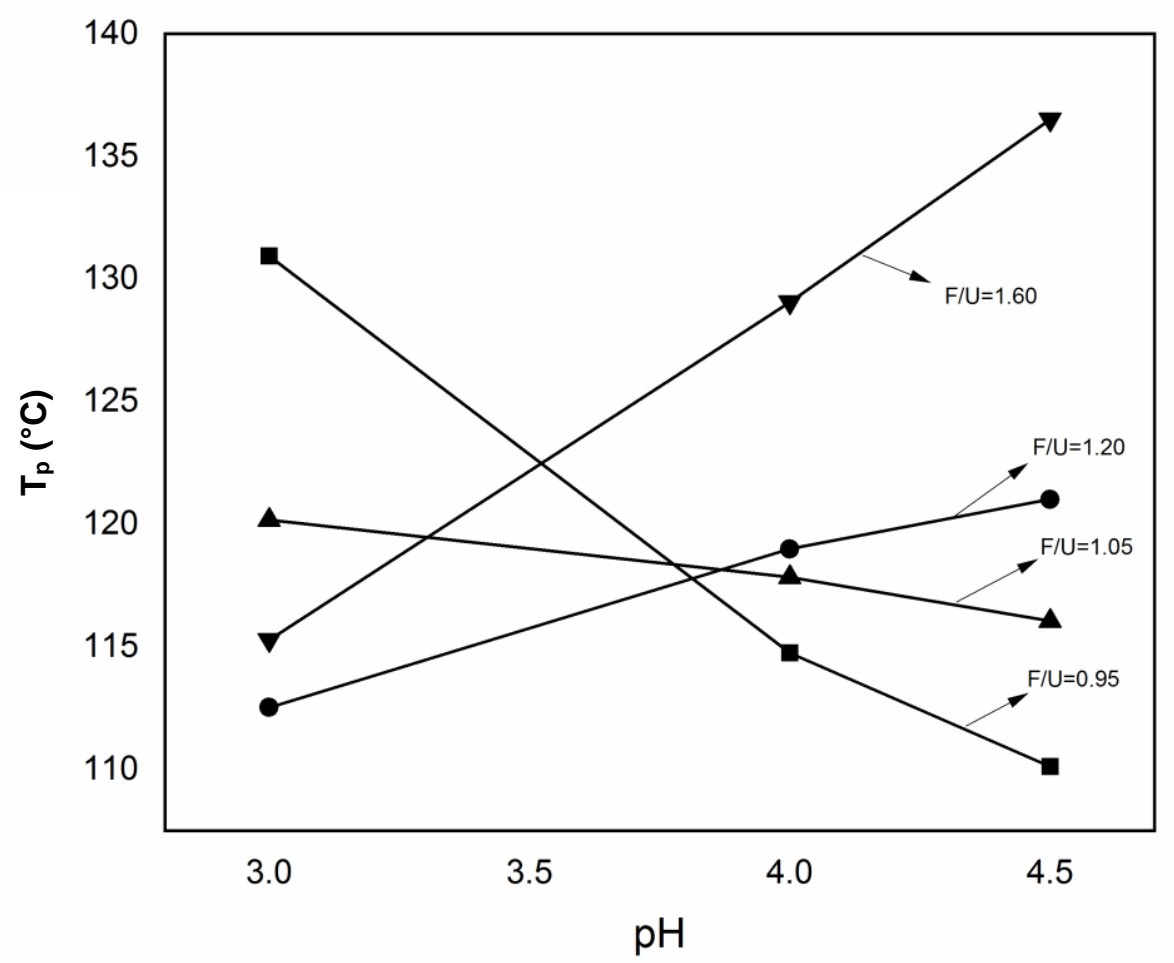

Fig. 12. $T_{p}$ of peak 2 on DSC curves of UF resin with different $F / U$ molar ratios of curing under condition of different $\mathrm{pH}$

\section{CONCLUSIONS}

1. Condensation reaction, and as well as crystallization, takes place during the ureaformaldehyde (UF) resin curing process. When the resin is cured with a higher F/U molar ratio, the condensation reaction happens before the aggregation of macromolecular chains of initial resin. The reaction increases the degree of branching of resin and weakens the crystallization. In contrast, when the resin is cured with a lower molar ratio, the aggregation and crystallization of macromolecular chains take place before the condensation reaction. The reaction enforces the crystallinity of the cured resin.

2. With the decrement of F/U molar ratios, the importance of the condensation reaction and importance of crystallization will gradually convert to each other in the course of the curing process. When the $\mathrm{F} / \mathrm{U}$ molar ratio is higher than 1.05 , the condensation reaction plays a major role. When the $\mathrm{F} / \mathrm{U}$ molar ratio is lower than 1.05 , the crystallization plays a major role. The turning point is around a mole ratio of 1.05.

3. The molar ratio, and as well as the $\mathrm{pH}$ condition, will affect the curing process through the condensation reactivity of the initial resin. The impact of the mole ratio on resin curing is larger than the impact of the $\mathrm{pH}$ condition. This indicates that the effect of the hardener on the properties of the cured resin is limited. 


\section{REFERENCES CITED}

Dazmiri, M. K., Kiamahalleh, M. V., Dorieh, A., and Pizzi, A. (2019). "Effect of the initial $\mathrm{F} / \mathrm{U}$ molar ratio in urea-formaldehyde resins synthesis and its influence on the performance of medium density fiberboard bonded with them," International Journal of Adhesion and Adhesives 102440. DOI:10.1016/j.ijadhadh.2019.102440

Ding, Z. J., and Tian, J. G. (2017). "Influence of $\mathrm{pH}$ condition on hydrolysis stability and crystallinity of cured urea-formaldehyde resin during curing process," Scientia Silvae Sinicae 53(12), 120-125. DOI: 10.11707/j.1001-7488.20171213

GB/T 14732-2006(2006). "Urea formaldehyde, phenolic formaldehyde, melamine formaldehyde resin for wood industry adhesives," Standardization Administration of China, Beijing, China.

Gupta, V. B., Drzal, L. T., Adams, W. W., and Omlor, R. (1985). "An electron microscopic study of the morphology of cured epoxy resin," Journal of Materials Science 20(10), 3439-3452.

Nuryawan, A., Singh, A. P., and Park, B. D. (2015). "Swelling behavior of cured ureaformaldehyde resin adhesives with different formaldehyde to urea mole ratios," The Journal of Adhesion 91, 677-700. DOI: 10.1080/00218464.2014.962022

Nuryawan, A., Singh, A. P., Park, B. D., and Causin, V. (2016). "Micro-morphological features of cured urea-formaldehyde adhesives detected by transmission electron microscopy," The Journal of Adhesion 92(2), 121-134.

Nuryawan, A., Singh, A. P., Zanetti, M., Park, B. D., and Causin, V. (2017). "Insights into the development of crystalline in liquid urea-formaldehyde resins," International Journal of Adhesion and Adhesives 72, 62-69. DOI: 10.1016/j.ijadhadh.2016.10.004

Park, B. D., Kang, E. C., and Park, J. Y. (2006). "Effects of formaldehyde to urea mole ratio on thermal curing behavior of urea-formaldehyde resin and properties of particleboard," Journal of Applied Polymer Science 101(3), 1787-1792. DOI: 10.1002/app. 23538

Park, B. D., and Jeong, H. W. (2011). "Hydrolytic stability and crystallinity of cured urea-formaldehyde resin adhesives with different formaldehyde/urea mole ratios," International Journal of Adhesion and Adhesives 31(6), 524-529. DOI: 10.1016/j.ijadhadh.2011.05.001

Park, B. D., and Causin, V. (2013). "Crystallinity and domain size of cured ureaformaldehyde resin adhesives with different formaldehyde/urea mole ratios," European Polymer Journal 49(2), 532-537. DOI: 10.1016/j.eurpolymj.2012.10.029

Siimer, K., Kalijuvee, T., and Chistjanson, P. (2003). "Thermal behavior of ureaformaldehyde resins during curing," Journal of Thermal Analysis and Calorimetry 72, 607-617. DOI: 10.1023/A:1024590019244

Singh, A. P., Causin, V., Nuryawan, A., and Park, B. D. (2014). "Morphological, chemical and crystalline features of urea-formaldehyde resin cured in contact with wood," European Polymer Journal 56, 185-193. DOI:

10.1016/j.eurpolymj.2014.04.014

Szesztay, M., Laszlo-Hedvig, Z., Kovacsovics, E., and Tüdős, F. (1993). "DSC application characterization of Urea/formaldehyde condensates," Holz als Roh- und Werkstoff 51, 297-300. DOI: 10.1007/BF02663798

Szesztay, M., Laszlo-Hedvig, Z., Nagy P., and Tüdős, F. (1996). “DSC application characterization of urea/formaldehyde condensates, II. Experiences with high pressure cell," Holz als Roh-und Werkstoff 53, 399-402. 
Xing, C., Deng, J., Zhang, S. Y., Riedl, B., and Cloutier A. (2005). "Differential scanning calorimetry characterization of urea-formaldehyde resin curing behavior as affected by less desirable wood material and catalyst content," J. Appl. Polym. Sci. 98, 20272032. DOI:10.1002/app.22118.

Zorba, T., Papadopoulou, E., Hatijiissaak, A., and Paraskevopoulos, K. M. (2008). "Ureaformaldehyde resins characterized by thermal analysis and FTIR method," Journal of Thermal and Calorimetry 92(1), 29-33.

Article submitted: December 4, 2019; Peer review completed: February 13, 2020;

Revised version received: March 4, 2020; Accepted: March 7, 2020; Published: March $10,2020$.

DOI: 10.15376/biores.15.2.2924-2936 